\title{
Broadband Corrugated Square-Shaped Monopole Antenna
}

\author{
S. D. Ahirwar and C. Sairam \\ Defence Electronics Research Laboratory, Chandrayangutta Lines, Hyderabad 500005, India \\ Correspondence should be addressed to S. D. Ahirwar, sdahirwar@rediffmail.com
}

Received 12 August 2010; Accepted 8 September 2010

Academic Editors: M. Y. W. Chia and G. Tsoulos

Copyright () 2011 S. D. Ahirwar and C. Sairam. This is an open access article distributed under the Creative Commons Attribution License, which permits unrestricted use, distribution, and reproduction in any medium, provided the original work is properly cited.

\begin{abstract}
Design and development of a corrugated square-shaped monopole antenna is presented with measured results. The operational bandwidth of the antenna is $300 \mathrm{MHz}-3000 \mathrm{MHz}$. The antenna is derived from a square-shaped planar monopole antenna. This basic square-shaped radiating element is corrugated in its lateral dimension. This corrugation reduces the lateral dimension of the antenna by $60 \%$. Electrical performance of this antenna is better than its parent counterpart. This paper presents design and performance characteristics of conventional square-shaped monopole and its derivative, that is, broadband corrugated squareshaped monopole antenna.
\end{abstract}

\section{Introduction}

The rapid advancements in communication technologies are the driving force in design and development of broadband antennas with desirable mechanical features like compact size and light weight. Monopole antennas, owing to their simple structure, small size, and feasibility of implementation in printed circuit form, are preferred for mobile platforms as well as in airborne applications [1]. Monopole antennas in planar form are more suitable to be enclosed in the aerodynamically shaped radomes. The monopole antennas utilize the skin of the platform as its ground plane. Conventional quarter wave monopole antenna is a narrowband antenna having bandwidth of operation of the order of $1 \%$ to $5 \%$ [2]. If any antenna structure is defined by angle (angular concept), then antenna will have broadband characteristics [3]. Biconical antenna and its variants are the conventional broadband antennas based on angular concept. These antennas require to be in full size $(\lambda / 4$ height for monopole antennas) for their operation. Scope of size reduction is much less in such type of antennas due to the above requirement. Realizing the radiating element in planar (printed) form is one of the ways to reduce the volume of the antenna. In planar form, the different shapes of radiating elements are proposed for monopole antennas to tailor and improve the impedance bandwidth of the antenna [47]. These antennas can provide extremely wide impedance bandwidth, but their pattern bandwidth is limited due to deteriorated radiation patterns at higher frequencies $[6,8]$. In the proposed antenna design, the pattern bandwidth is improved by modifying the planar radiating element into a corrugated one. The impedance of the antenna is much wider, but the operational bandwidth of this antenna is $10: 1$.

\section{Antenna Design and Realization}

The input impedance of the conical monopole antenna is given by

$$
\text { Zin }=60 \ln \left[\cot \left(\frac{\theta}{4}\right)\right] \Omega \text {, where } \theta \text { is the cone angle. }
$$

The planar radiating element is chosen in square form. One of the corners of this element is used as a feed end, and hence the angle of the planar radiating element is $90^{\circ}$. The above equation for input impedance of the antenna is valid only if the antenna structure is 3-dimensional and its height is infinity. For limited-size antennas, the lower operatingfrequency of the antenna is decided by the antenna size. The edge size of the square is chosen as $0.12 \lambda$ at lower frequency of operation $(300 \mathrm{MHz})$ due to size constraints. The antenna dimensions (width $\times$ height) are $0.17 \lambda \times 0.17 \lambda$.

The antenna was realized using semi-flexible copper cladrded RT Duroid (thickness $=0.5 \mathrm{~mm}, \varepsilon_{r}=2.2$ ). The 


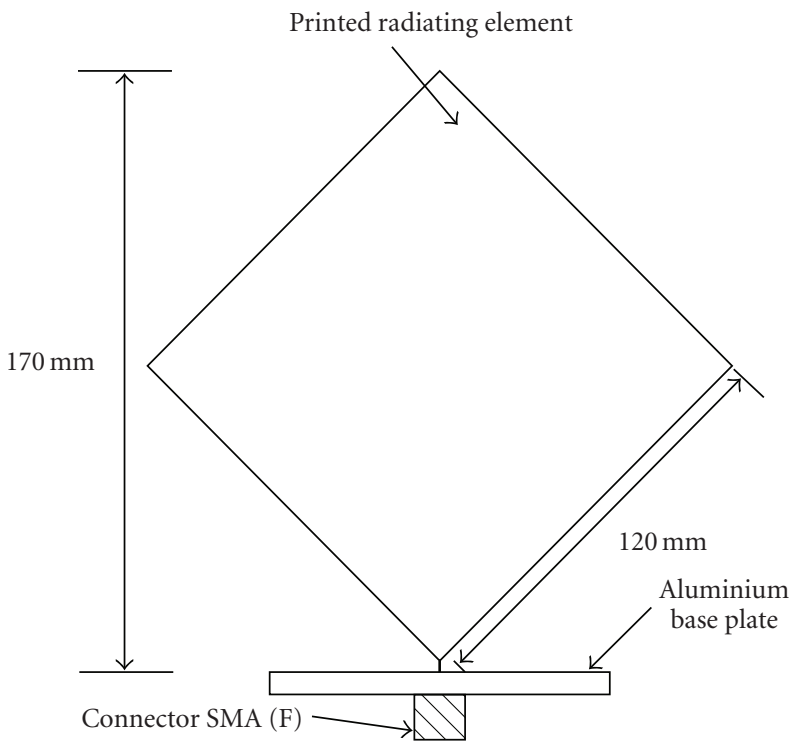

FIGURE 1: Schematic of planar square-shaped element monopole antenna.

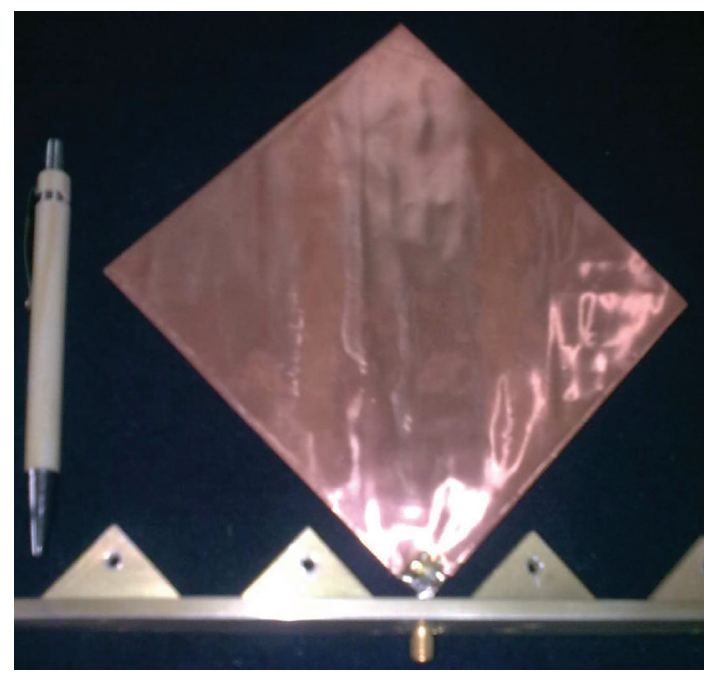

FIgURE 2: Photograph the of planar square-shaped element monopole antenna.

metallization on this substrate is used as a radiating element of dimensions $120 \mathrm{~mm} \times 120 \mathrm{~mm}$. The diagonal dimensions of this element are $170 \mathrm{~mm} \times 170 \mathrm{~mm}$. An aluminum base plate in elliptical shape was fabricated to hold the connector and provide interface to ground plane. The SMA (F) connector was used for excitation of the antenna. The centre pin of connector is connected to the printed radiating element of the antenna and the outer to the aluminum base plate. The schematic of this antenna and its photograph are shown in Figures 1 and 2, respectively. This antenna was transformed into corrugated radiating element monopole antenna. The corrugations are provided in lateral dimension of the radiating element. Because of this, the planar laminate with printed element is folded to transform it in a wavy (sinusoidal) surface. The 5 corrugations were used with a corrugation pitch of $13.7 \mathrm{~mm}$ and height of corrugation $27 \mathrm{~mm}$. The dimensions in this new antenna are modified to $170 \mathrm{~mm} \times 68.5 \mathrm{~mm} \times 27 \mathrm{~mm}$ (height $\times$ width $\times$ thickness). The outer dimensions and photograph of the designed and developed corrugated radiating element antenna are shown in Figures 3(a) and 3(b), respectively. To compare the performance of this proposed antenna to a conventional monopole antenna, a monopole antenna of dimensions $(170 \mathrm{~mm} \times 68.5 \mathrm{~mm} \times 27 \mathrm{~mm})$ similar to corrugated element monopole was also fabricated.

\section{Results and Discussion}

The antennas were evaluated for their impedance characteristics using M/s R\&S ZVRE vector network analyzer model no.1043.0009. A circular ground plane of diameter 


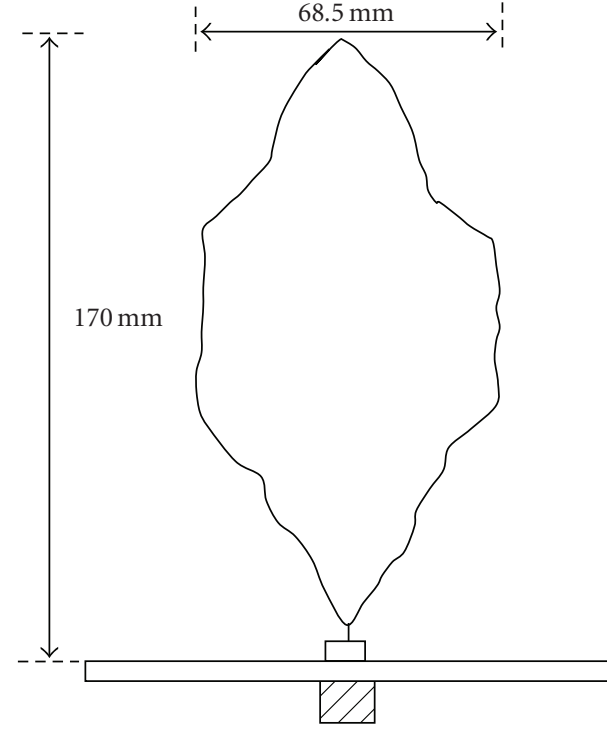

(a)

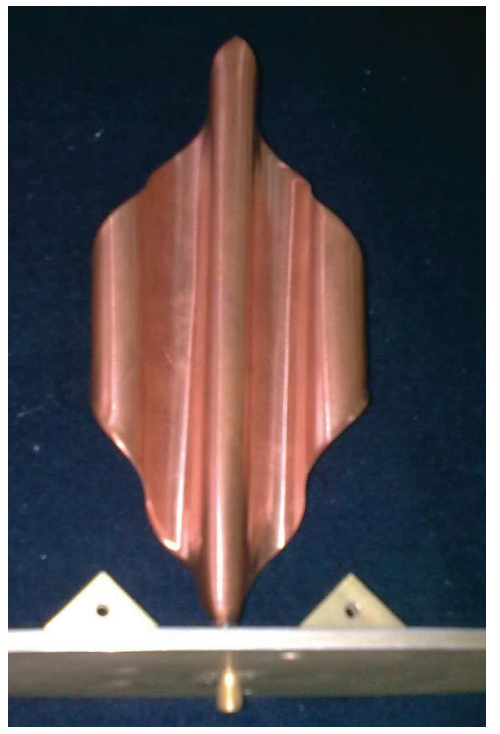

(b)

FIgURE 3: (a) Outer dimensions of the corrugated radiating element monopole antenna. (b). Photograph of the corrugated radiating element monopole antenna.

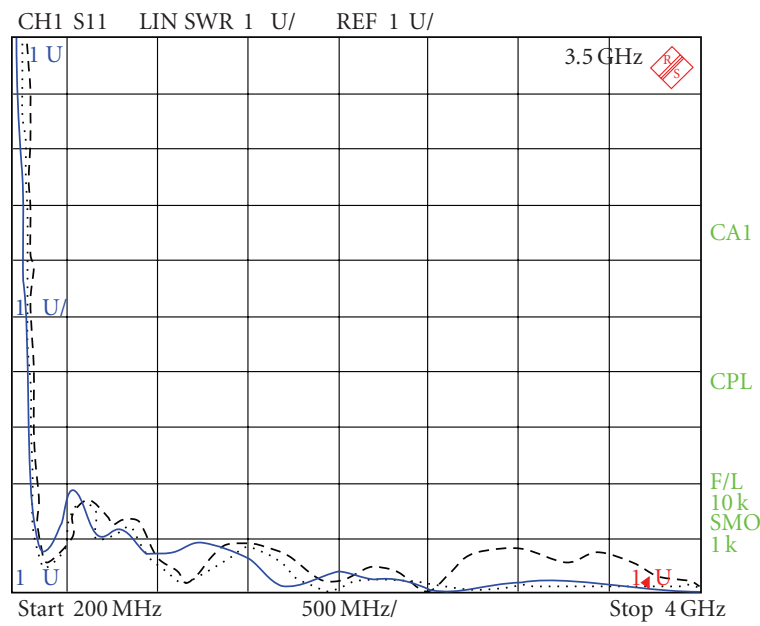

_... Planar square radiating element
- - - Corrugated radiating element

FIGURE 4: VSWR plots of square monopole, corrugated monopole and conventional monopole antennas.

$400 \mathrm{~mm}$ was used for antenna evaluation. The comparisons of measured VSWR plots for three antennas (squareshaped planar monopole antenna, corrugated monopole antenna, and conventional monopole antenna) are shown in Figure 4 .

The measured VSWR values for square monopole, corrugated monopole, and conventional monopole are $3.4: 1,3.5: 1$, and $4.5: 1$, respectively, at lowest frequency of operation $(300 \mathrm{MHz})$. The difference between the values of VSWR of square and corrugated monopoles is only 0.1 . This difference is 1 for conventional one. This shows that the VSWR profiles for square and corrugated monopoles are almost similar, while conventional monopole of similar dimension to corrugated one has higher VSWR values. The corrugated antenna was also examined with different number of corrugations, corrugation pitches and heights. It is observed that the antenna is not much sensitive for these variations as far as impedance is concerned. The variation in impedance is observed with major variations in these parameters. For instance, with larger pitch of the corrugation and lesser corrugation height, the antenna characteristics move toward planar antenna, and with lesser pitch more 


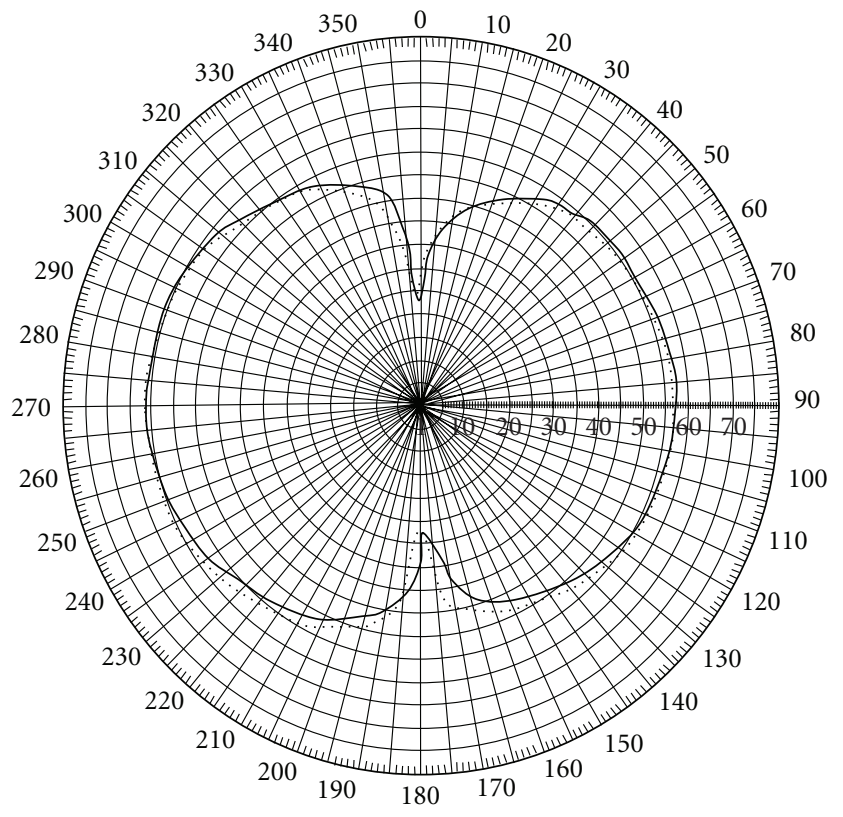

- Square planar monopole antenna
$\ldots .$. Corrugated monopole antenna

(a) Frequency: $300 \mathrm{MHz}$

Far-field amplitude of coru_E.nsi

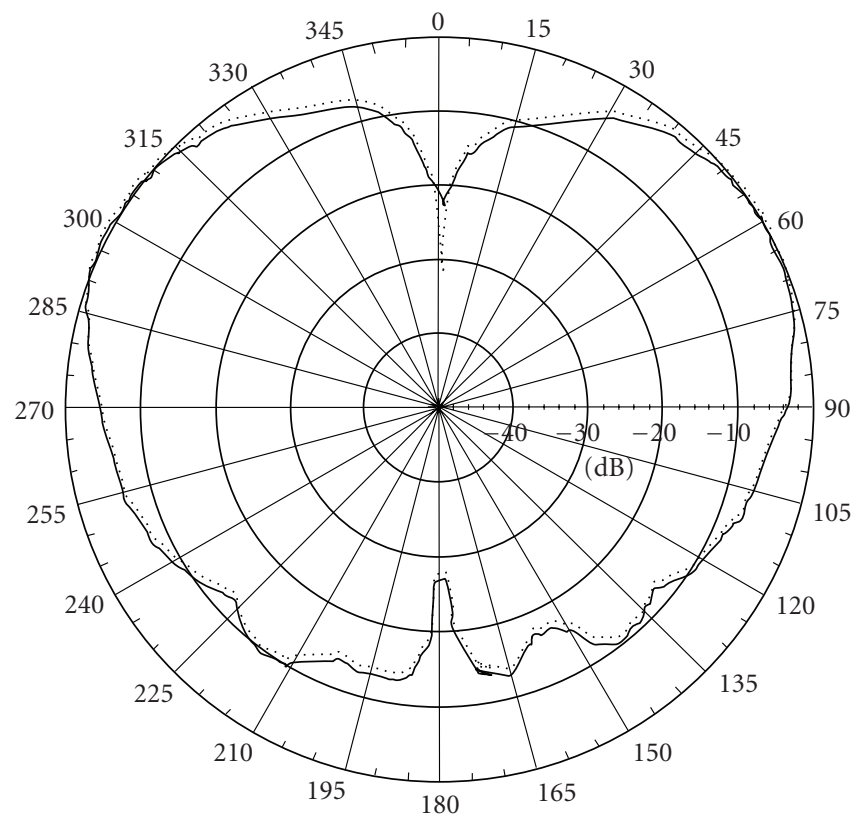

- Corru_0.6 GHz

…. Diam_0.6 GHz

(c) Frequency: $600 \mathrm{MHz}$

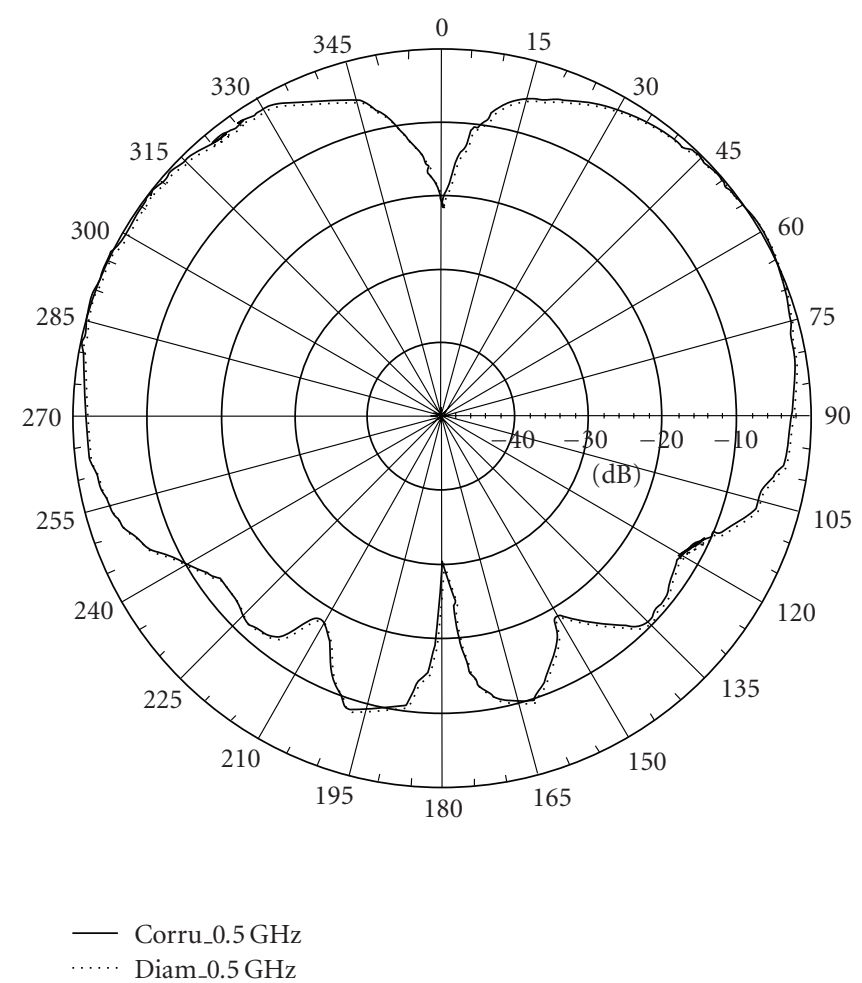

(b) Frequency: $500 \mathrm{MHz}$

Far-field amplitude of coru_E.nsi

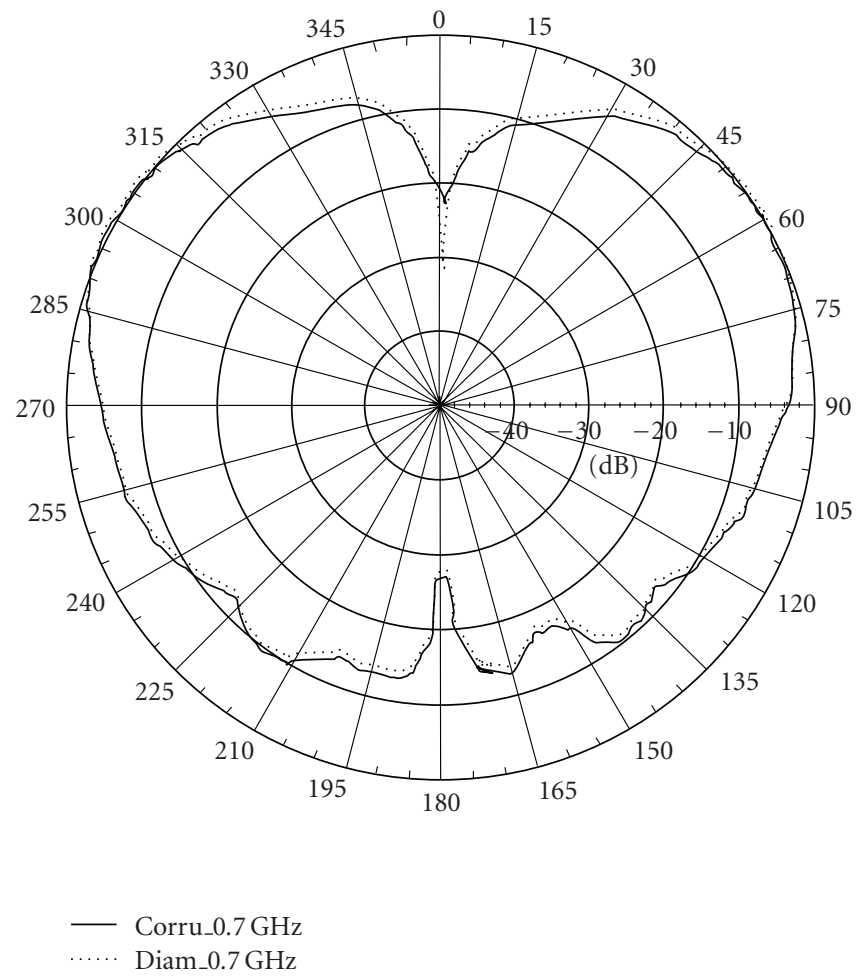

(d) Frequency: $700 \mathrm{MHz}$

Figure 5: Continued. 
Far-field amplitude of coru_E.nsi

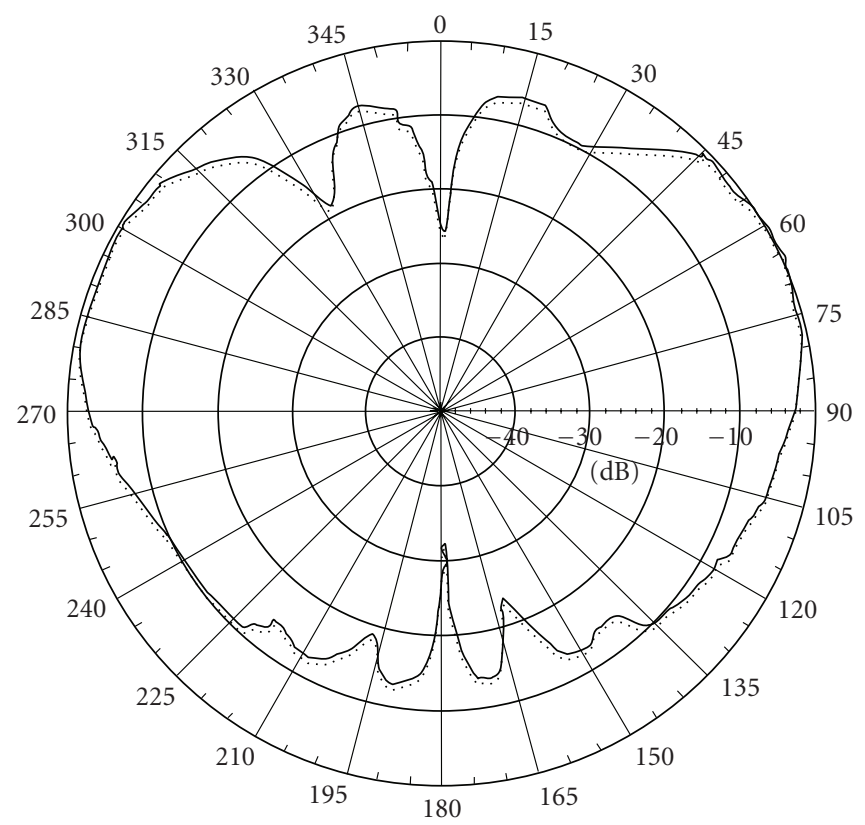

- Corru $\_0.8 \mathrm{GHz}$

..... Diam_0.8 GHz

(e) Frequency: $800 \mathrm{MHz}$

Far-field amplitude of coru_E.nsi

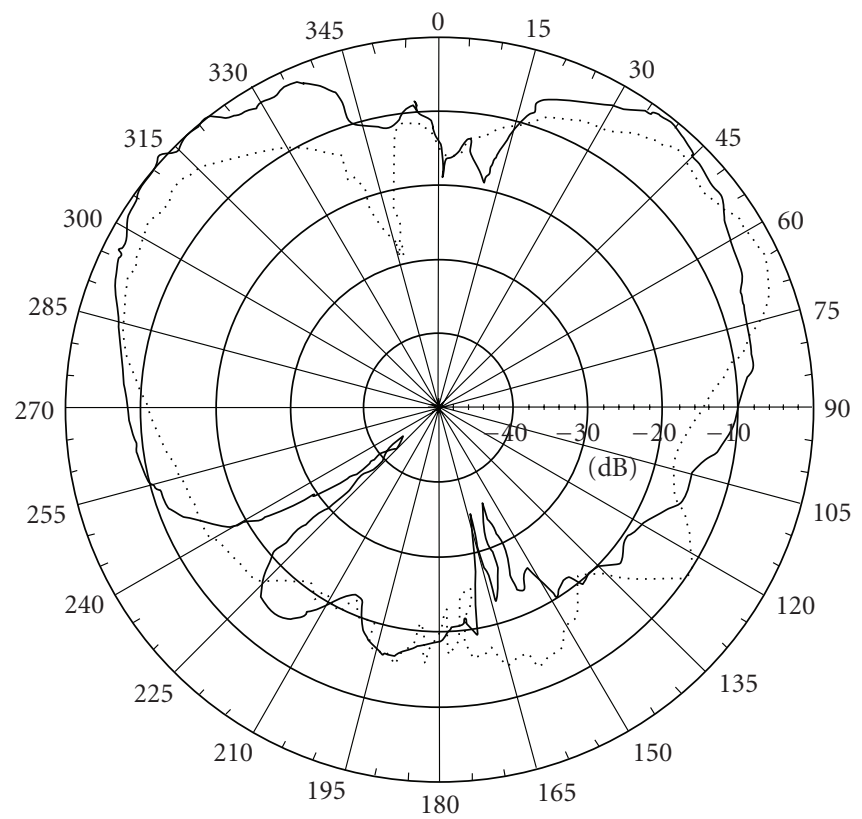

- Corru_2.2 GHz

..... Diam_2.2 GHz

(g) Frequency: $2200 \mathrm{MHz}$
Far-field amplitude of coru_E.nsi

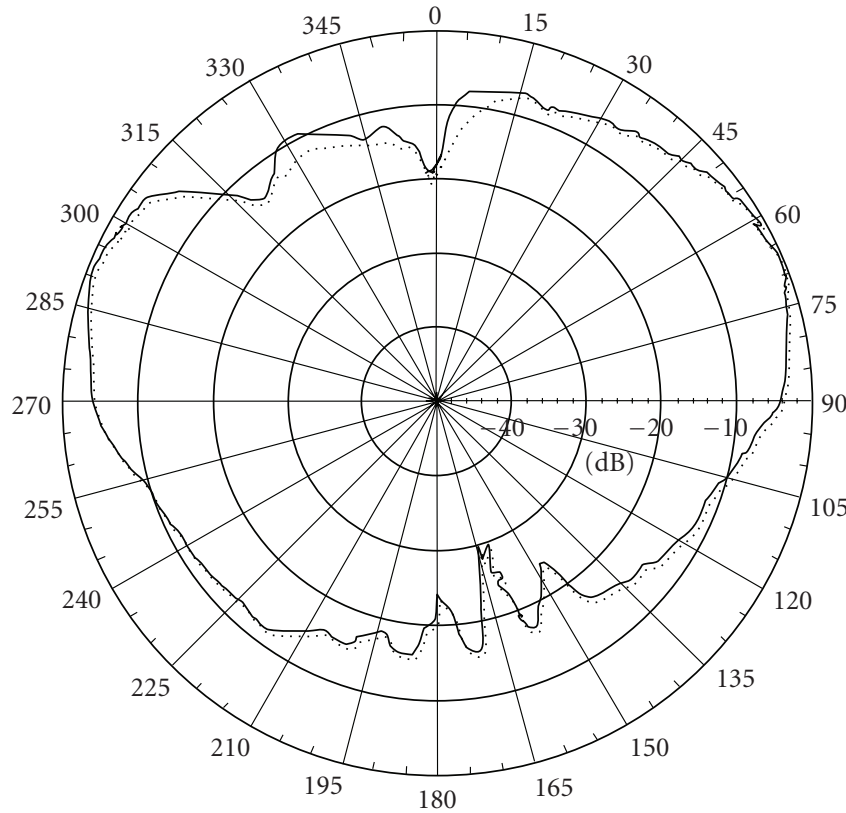

- Corru_1 GHz

….. Diam_1 GHz

(f) Frequency: $1000 \mathrm{MHz}$

Far-field amplitude of coru_E.nsi

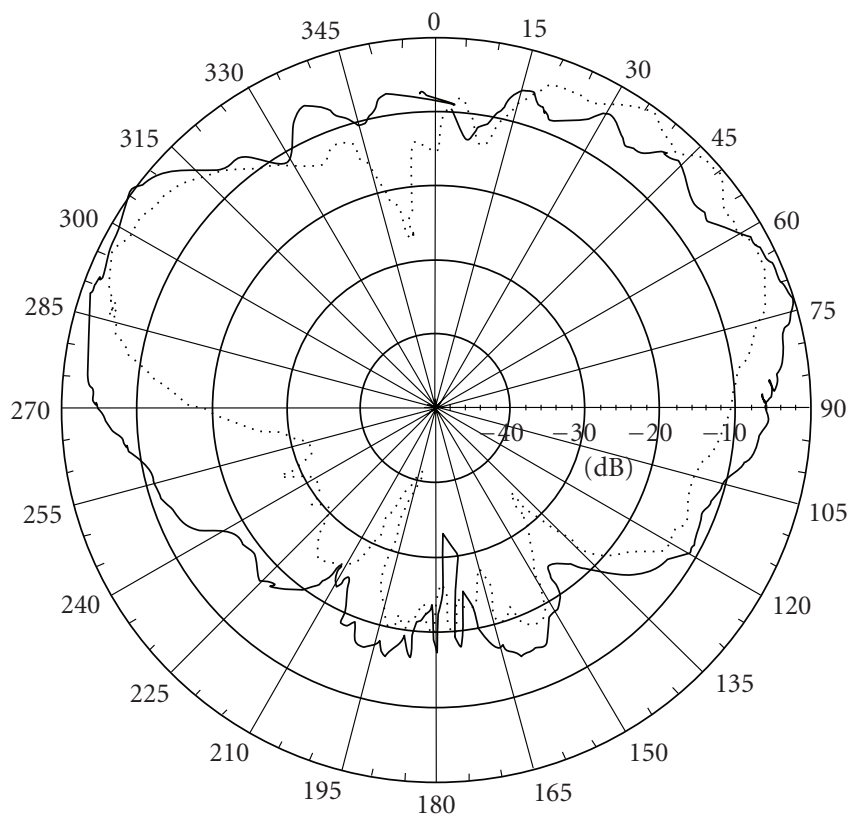

- Corru_2.6 GHz

…. Diam_2.6 GHz

(h) Frequency: $2600 \mathrm{MHz}$

Figure 5: Continued. 
Far-field amplitude of coru_E.nsi

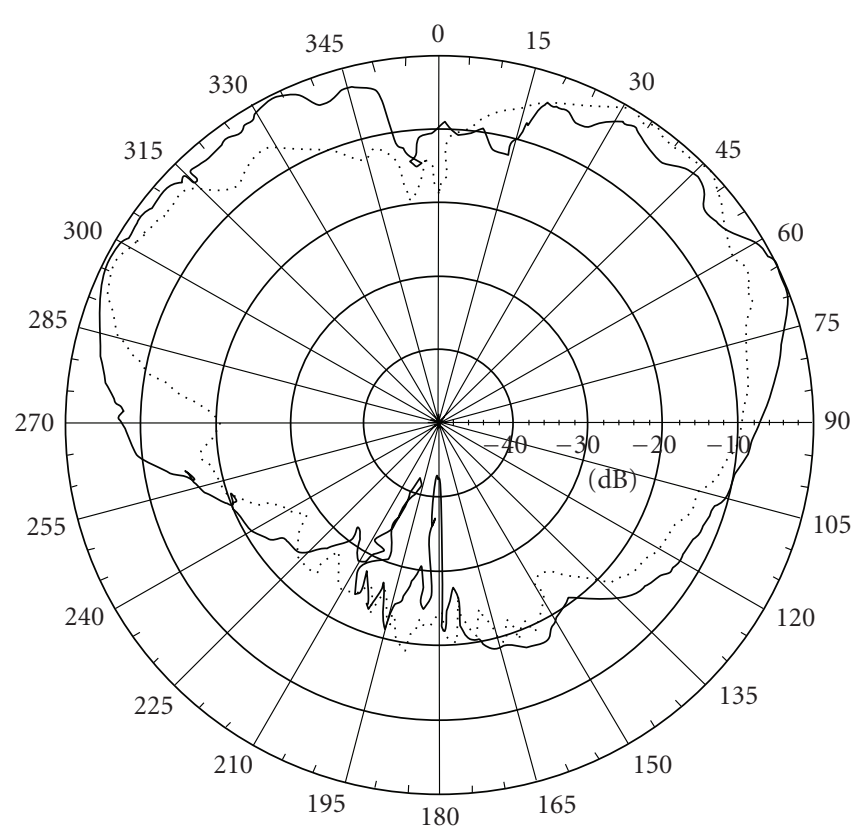

$\begin{array}{ll}- & \text { Corru_2.8 GHz } \\ \ldots . & \text { Diam_2.8 GHz }\end{array}$

(i) Frequency: $2800 \mathrm{MHz}$
Far-field amplitude of coru_E.nsi

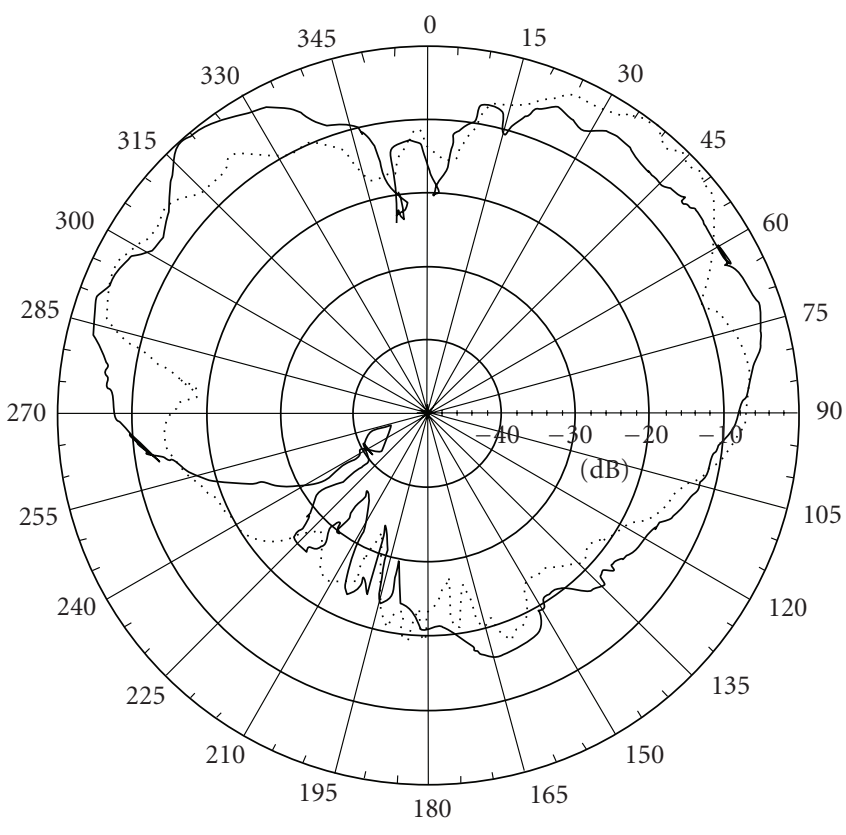

- Corru_3 GHz Diam_3 GHz

Figure 5: Measured elevation plane radiation patterns of corrugated and square monopole antennas.

corrugation height and antenna behaves like cylindrical element monopole antenna.

The antennas were evaluated for their radiation characteristics in ground reflection antenna test range below $500 \mathrm{MHz}$ frequency range and in anechoic chamber above $500 \mathrm{MHz}$ frequency band. The overlapped measured elevation plane radiation patterns of planar square/diamond monopole antenna and its corrugated monopole counterpart are shown in Figures 5(a)-5(j). These patterns are almost identical up to $1000 \mathrm{MHz}$ frequency range and show same gain for both antennas. Above $1000 \mathrm{MHz}$ frequency band the patterns related to planar square monopole show more undulation at horizon causing variation in gain and limited elevation coverage. For corrugated monopole antenna, the radiation patterns are smoother with larger elevation coverage with reference to horizon. The gain of corrugated monopole is $2-8 \mathrm{~dB}$ more (at horizon) than square-shaped monopole in the frequency range of $2200-3000 \mathrm{MHz}$. This feature of this antenna makes it superior due to large elevation coverage and better gain at horizon.

The measured azimuth plane radiation patterns are shown in Figures 6(a)-6(j). As evidenced from these plots, the omni deviation is much less $(\leq \pm 1 \mathrm{~dB}$ for corrugated, $\leq \pm 2 \mathrm{~dB}$ for square) up to $800 \mathrm{MHz}$ for both antennas. This omnideviation increases at higher frequencies. This is $\pm 2 \mathrm{~dB}$ at $1000 \mathrm{MHz}$ for corrugated monopole and $\pm 3 \mathrm{~dB}$ for square monopole. For square monopole antenna, the omni deviation is $> \pm 3 \mathrm{~dB}$ above $1000 \mathrm{MHz}$. For instance it is $\pm 8 \mathrm{~dB}$ at $2200 \mathrm{MHz}, \pm 11.5 \mathrm{~dB}$ at $2600 \mathrm{MHz}$, and $\pm 8 \mathrm{~dB}$ at $3000 \mathrm{MHz}$. For corrugated monopole antenna, the omni deviation remains $\leq \pm 3 \mathrm{~dB}$ up to $2200 \mathrm{MHz}$ frequency band. It is $\pm 3.5 \mathrm{~dB}$ at $2600 \mathrm{MHz}$, and $\pm 7 \mathrm{~dB}$ at $3000 \mathrm{MHz}$. The omni deviation in azimuth plane radiation is the most important factor in omnidirectional antennas. Considering the omnidirectionality of the antenna, the corrugated element monopole antenna performs better.

\section{Conclusions}

A broadband monopole antenna consisting of square-shaped planar radiating element has been designed and developed. A corrugated radiating element monopole antenna has been derived from square-shaped monopole antenna. Both these antennas were compared for their electrical characteristics. It is observed that the performance of corrugated element monopole was better than its parent (square monopole) counterpart. The corrugated monopole shows better gain at horizon and lesser omni deviation. Although there is good impedance match for both the antennas up to $4000 \mathrm{MHz}$ and more, pattern bandwidth is limited. The operating bandwidth of corrugated element monopole was much larger (about 10:1) than the planar element monopole antenna (about $4: 1$ ). The proposed corrugated squareshaped monopole antenna is compact and electrically small 
Far-field amplitude of coru_H.nsi

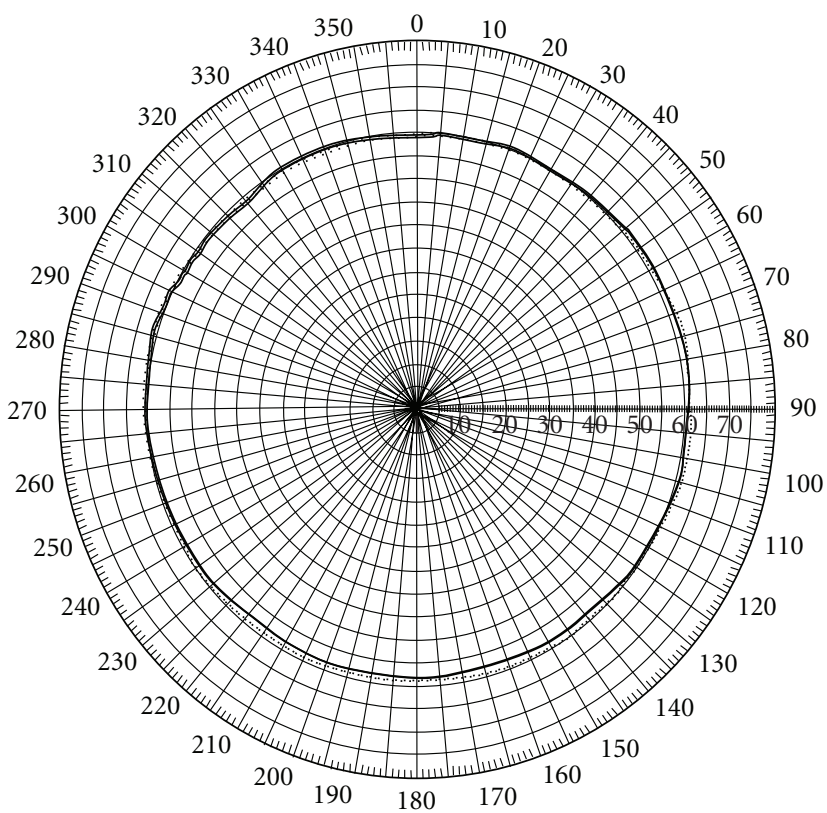

- Square planar monopole antenna
.... Corrugated monopole antenna

(a) Frequency: $300 \mathrm{MHz}$

Far-field amplitude of coru_H.nsi

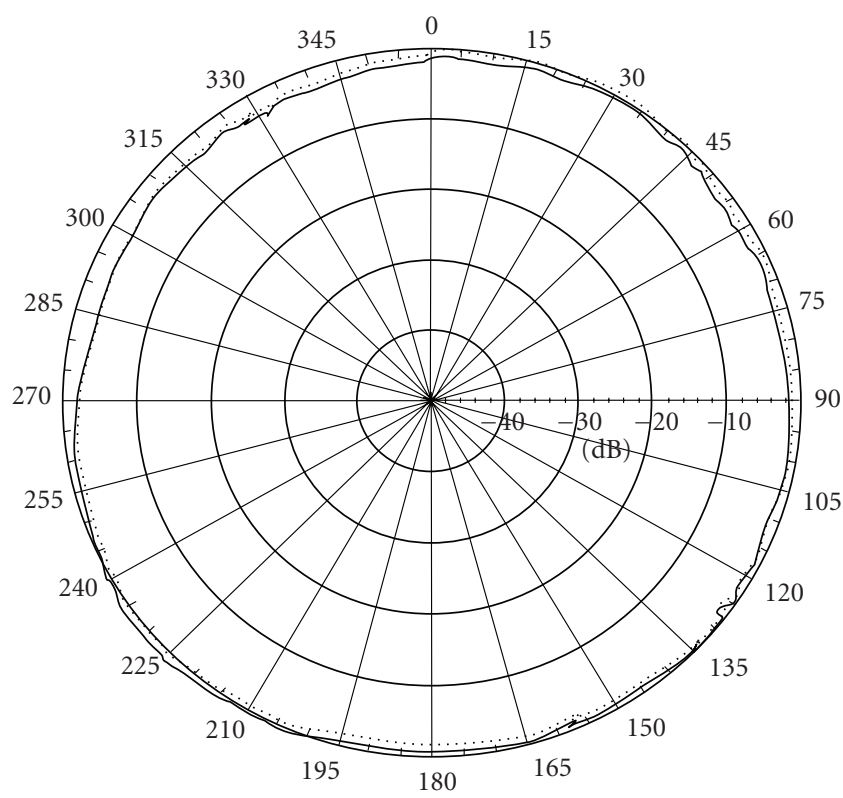

- Corru_H_0.6 GHz Diam_H_0.6 GHz

(c) Frequency: $600 \mathrm{MHz}$

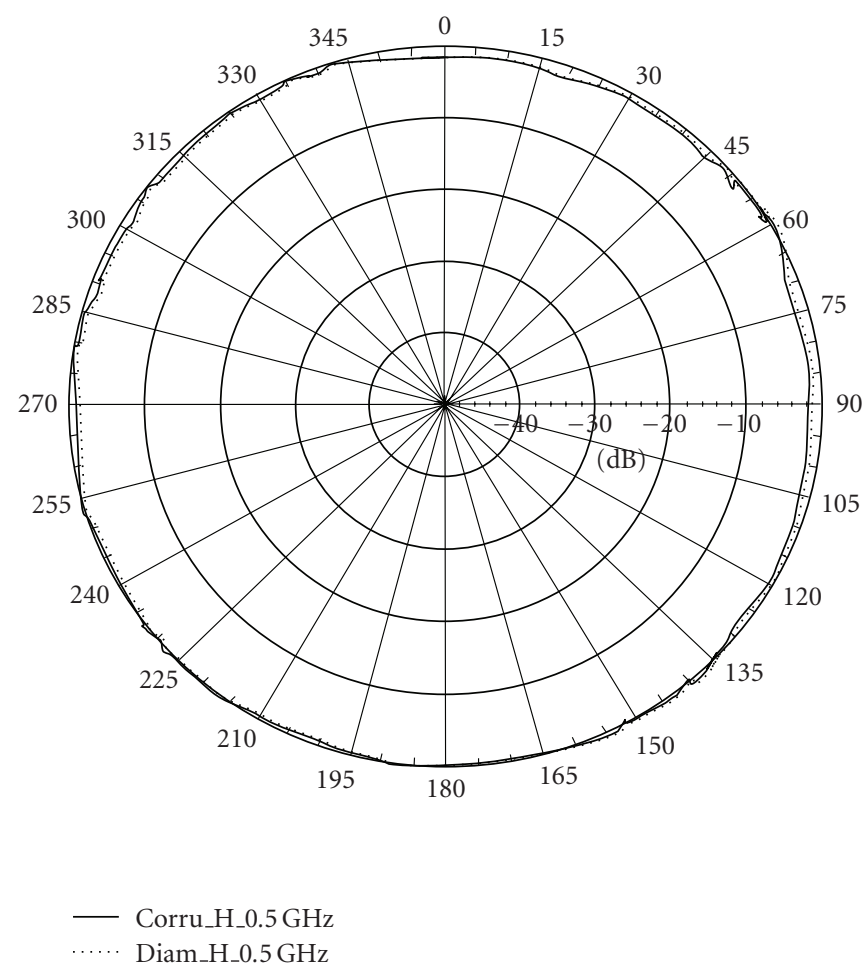

(b) Frequency: $500 \mathrm{MHz}$

Far-field amplitude of coru_H.nsi

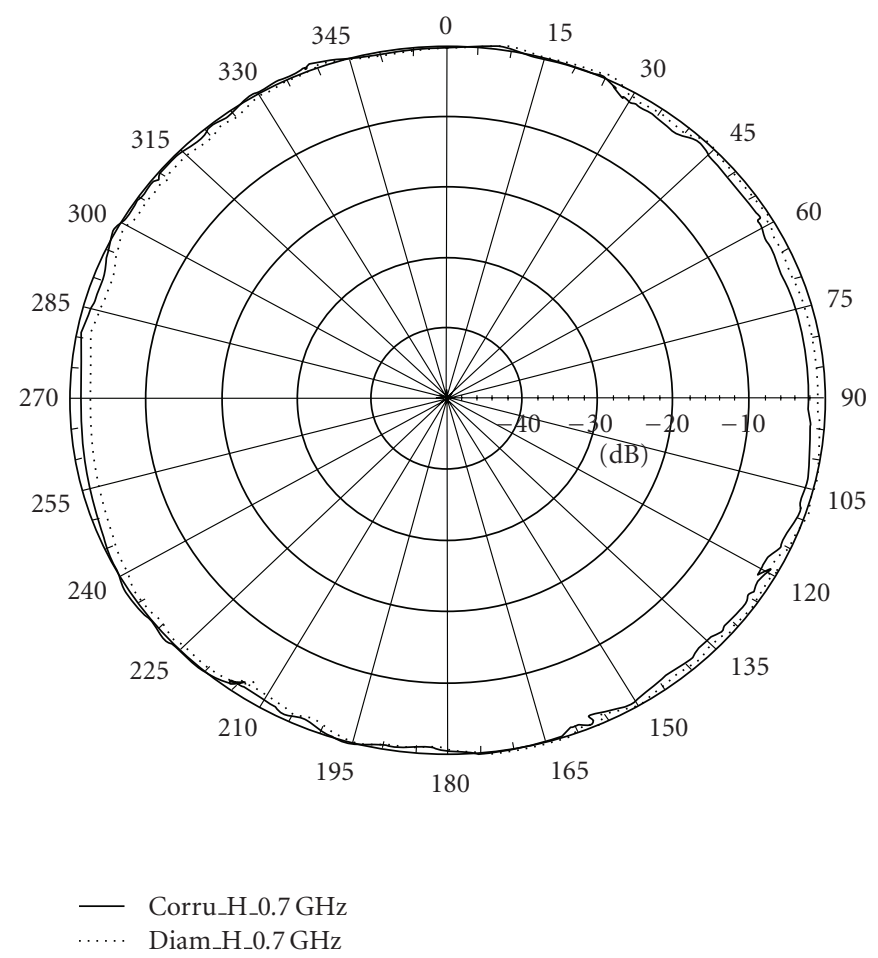

(d) Frequency: $700 \mathrm{MHz}$

Figure 6: Continued. 
Far-field amplitude of coru_H.nsi

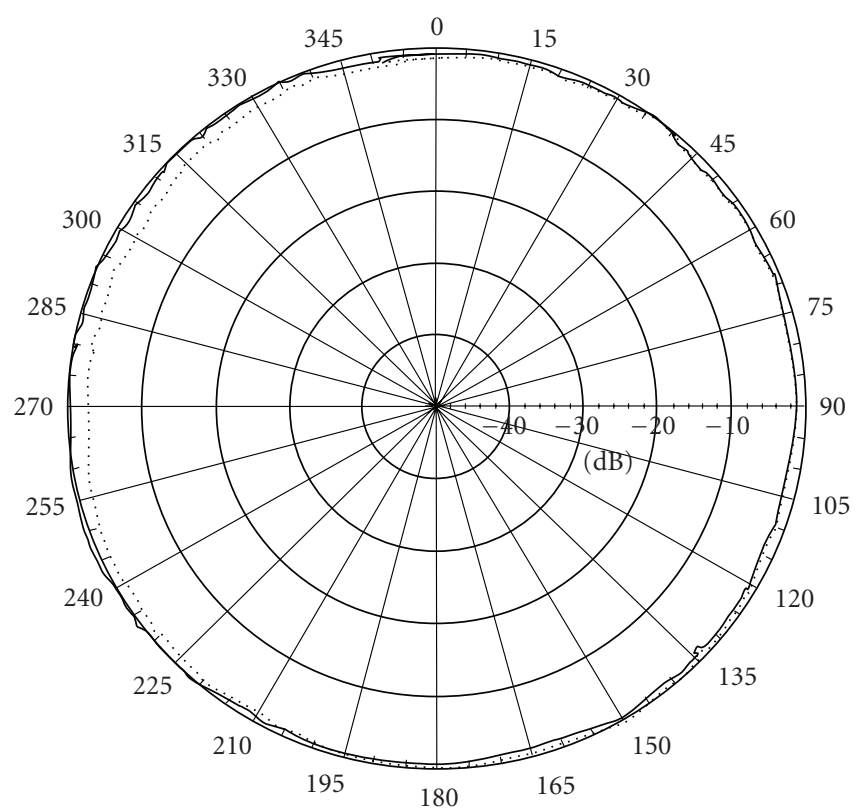

- Corru_H_0.8 $\mathrm{GHz}$

(e) Frequency: $800 \mathrm{MHz}$

Far-field amplitude of coru_H.nsi

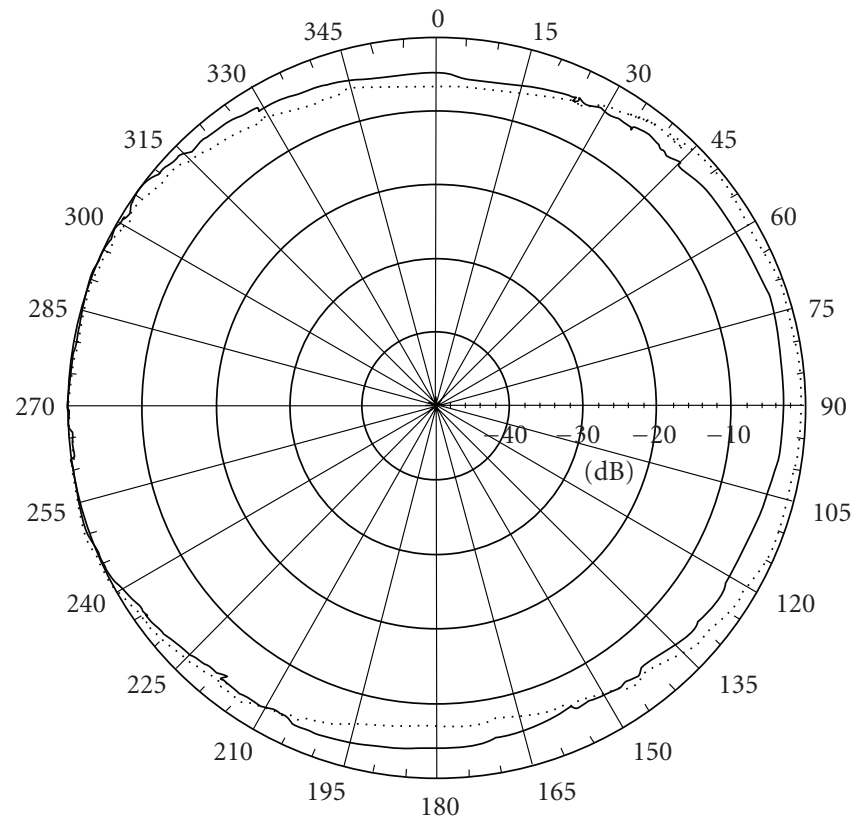

- Corru_H_1.9GHz

(g) Frequency: $1900 \mathrm{MHz}$
Far-field amplitude of coru_H.nsi

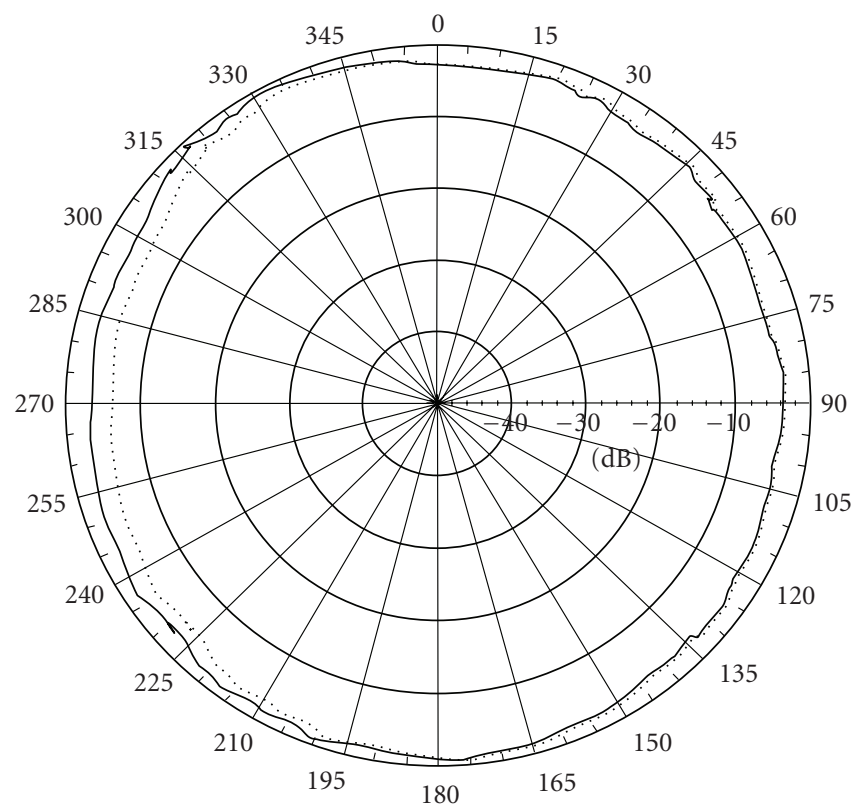

- Corru_H_1 GHz

..... Diam_H_1 GHz

(f) Frequency: $1000 \mathrm{MHz}$

Far-field amplitude of coru_H.nsi

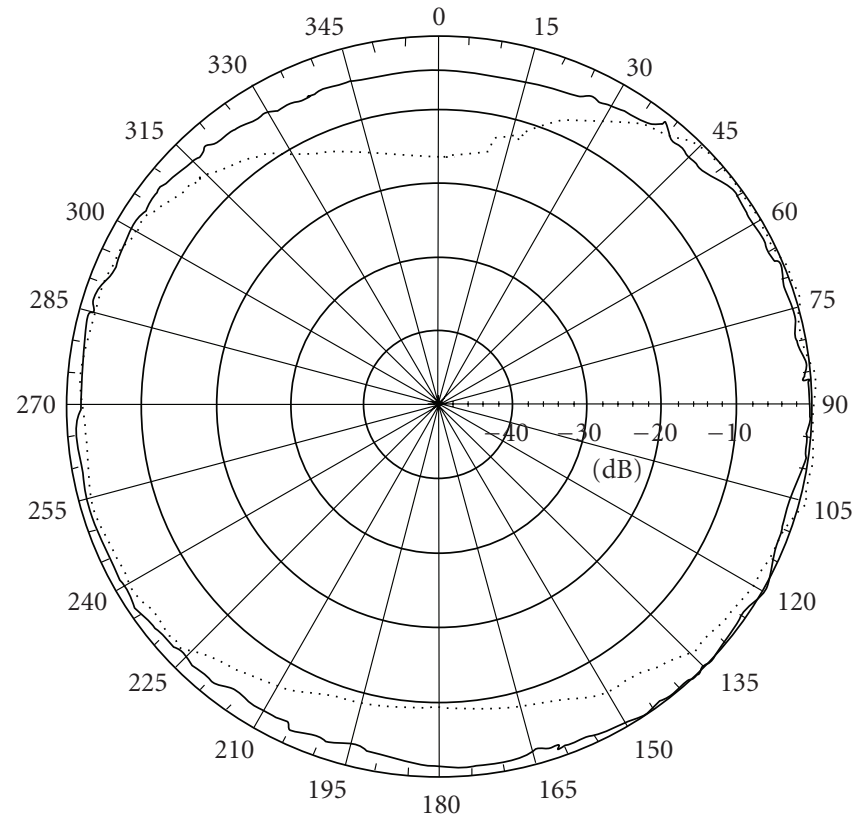

- Corru_H_2.2 GHz

.... Diam_H_2.2 GHz

(h) Frequency: $2200 \mathrm{MHz}$

FIgURE 6: Continued. 
Far-field amplitude of coru_H.nsi

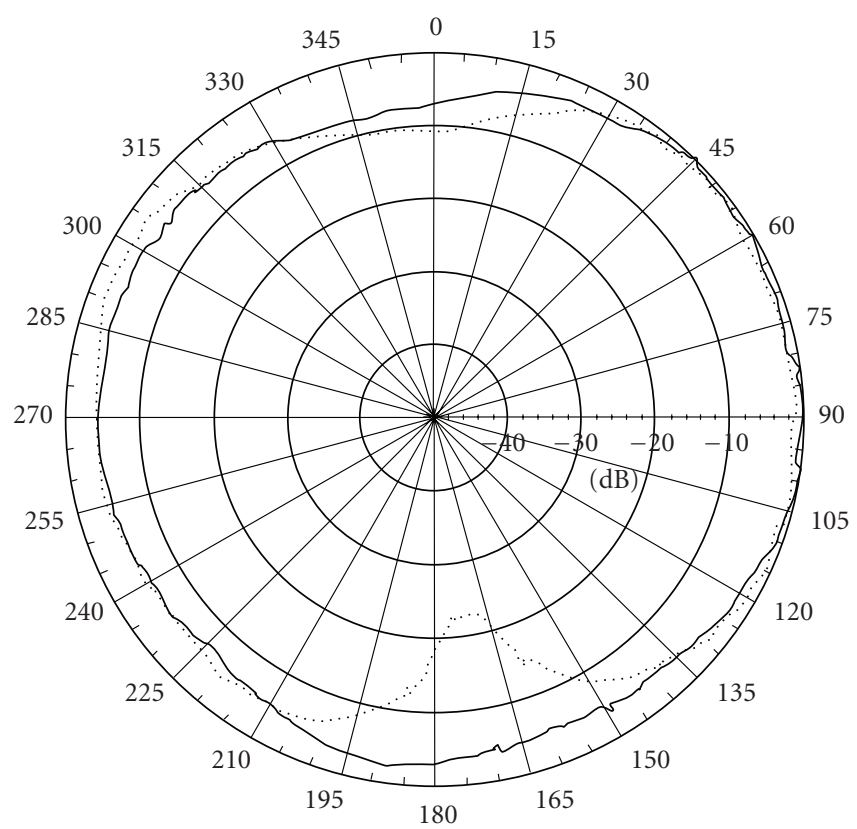

C... Corru_H_2.6 GHz
Diam_H_2.6 GHz

(i) Frequency: $2600 \mathrm{MHz}$
Far-field amplitude of coru_H.nsi

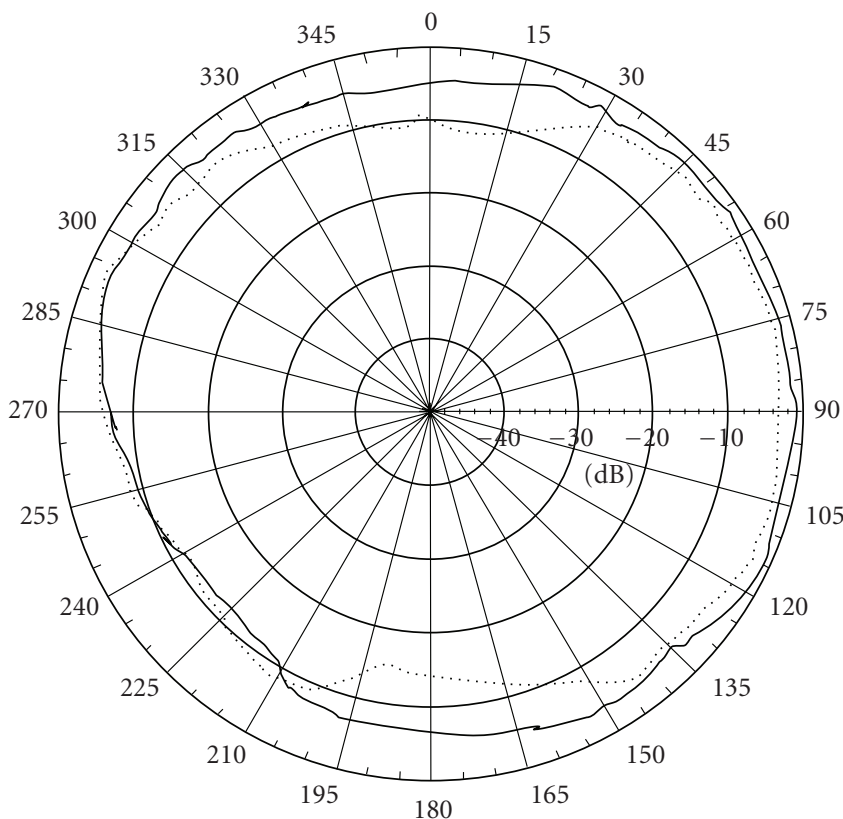

- Corru_H_3 GHz

… Diam_H_3 GHz

(j) Frequency: $3000 \mathrm{MHz}$

FIGURE 6: Measured azimuth plane radiation patterns of corrugated and square monopole antennas.

and finds use for trans-receive role in land and in mobile and airborne communication system for civil and defence applications.

\section{Acknowledgments}

The authors express their sincere thanks to Shri G. Boopathy, Director, DLRL for providing encouragement and motivation. they also would like to thank Shri KR Sundaram, Sc'G, Director, Technologies, and Shri M. balachary, Sc'G, Head of Antenna Wing, for their guidance and support to carry out this work.

\section{References}

[1] C. Sairam, T. Khumanthem, S. D. Ahirwar, and A. Kumar, "Design and development of broadband blade monopole antenna," in Proceedings of the International Conference of Recent Advances in Microwave Theory and Applications (MICROWAVE '08), pp. 150-151, Jaipur, India, November 2008.

[2] C. A. Balanis, Antenna Theory, Analysis and Design, John Willey \& Sons, New York, NY, USA, 2nd edition, 1998.

[3] C. E. Smith, Log Periodic Antenna Design Handbook, Smith Electronics, Cleveland, Ohio, USA, 1st edition, 1966.

[4] K. P. Ray, P. V. Anob, R. Kapur, and G. Kumar, "Broadband planar rectangular monopole antennas," Microwave and Optical Technology Letters, vol. 28, no. 1, pp. 55-59, 2001.
[5] N. P. Agrawall, G. Kumar, and K. P. Ray, "Wide-band planar monopole antennas," IEEE Transactions on Antennas and Propagation, vol. 46, no. 2, pp. 294-295, 1998.

[6] J. A. Evans and M. J. Ammann, "Planar trapezoidal and pentagonal monopoles with impedance bandwidths in excess of 10:1," in Proceedings of the IEEE International Symposium on Antennas and Propagation, vol. 3, pp. 1558-1561, Orlando, Fla, USA, 1999.

[7] S. N. Khan, L. Ti, J. Hu, and S. He, "A diamond-like vertical monopole antenna for ultra-wideband communication," Microwave and Optical Technology Letters, vol. 49, no. 10, pp. 2443-2446, 2007.

[8] C. T. P. Song, P. S. Hall, and H. Ghafouri-Shiraz, "Multiband multiple ring monopole antennas," IEEE Transactions on Antennas and Propagation, vol. 51, no. 4, pp. 722-729, 2003. 

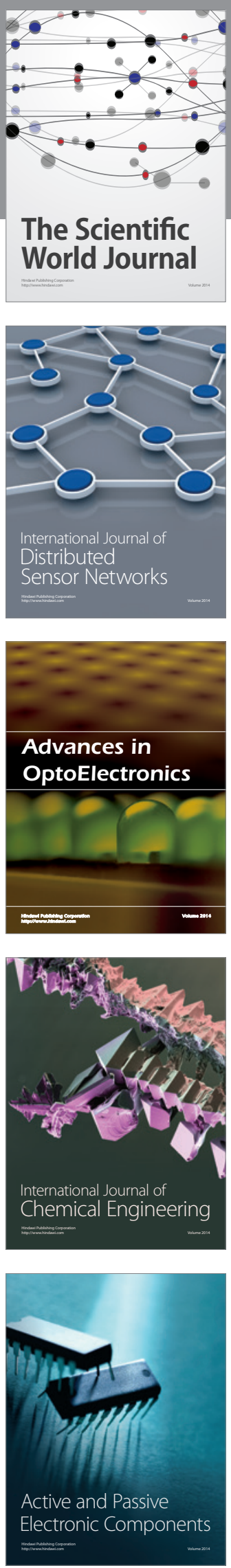
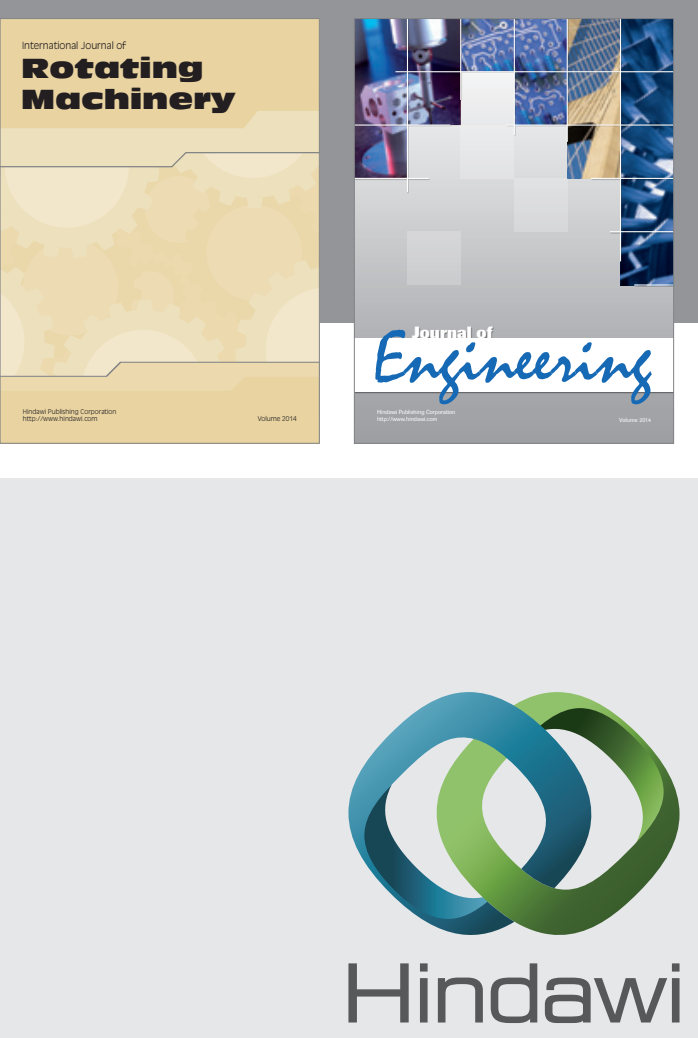

Submit your manuscripts at

http://www.hindawi.com
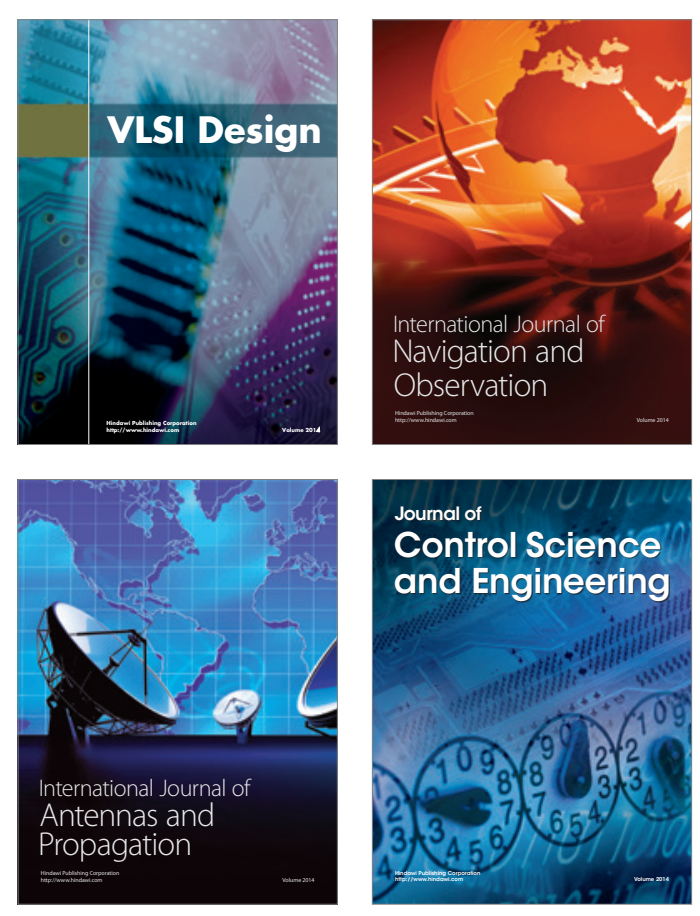
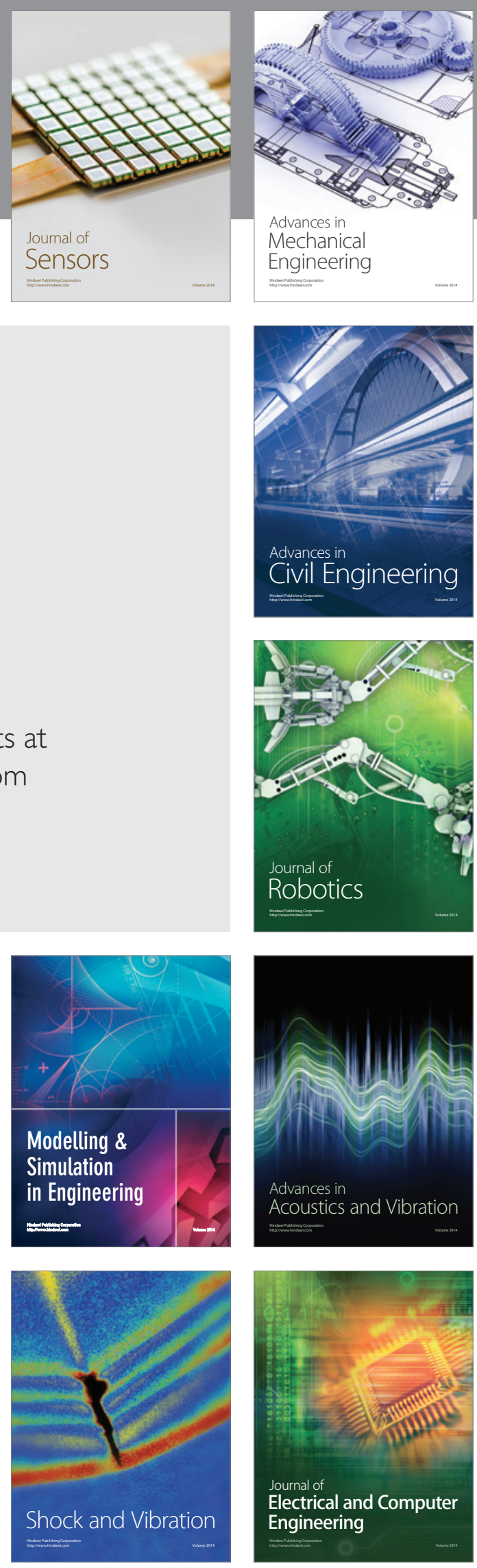